crecimiento invasivo con rápida diseminación sistémica; sólo encontramos 14 casos de CCC de bajo grado similares a nuestro caso $^{6}$. En los de alto grado la supervivencia cáncer específica a 3 años es del 45,3\%, y la supervivencia media tras la nefrectomía de 10,5 meses ${ }^{1,7}$. En el examen histológico el CCC forma estructuras tubulopapilares; la localización, la hiperplasia del epitelio de los túbulos colectores adyacentes al tumor y las características inmunohistoquímicas del mismo permiten su diagnóstico. Esto ha llevado a algunos grupos a considerar el tumor de los conductos de Bellini como una entidad independiente de los tumores de células renales, probablemente más próxima al tumor transicional del tracto urinario superior.

La tendencia actual es aplicar tratamientos quimiotérapicos similares a los de los tumores infiltrantes de células de células transicionales ${ }^{4}$. Recientemente se han publicado los resultados de un ensayo clínico en fase II con Gemcitabina y Cisplatino, observando una remisión completa y 5 parciales (supervivencia libre de enfermedad 7,1 meses y supervivencia global 10,5 meses) ${ }^{7}$.

Las características embriológicas, histológicas e inmunohistoquímicas convierten al CCC, en la mayoría de las ocasiones, en un tumor agresivo que se presenta en estadios avanzados donde la nefrectomía es insuficiente. La tendencia actual es administrar regímenes quimioterápicos similares a los de los carcinomas transicionales infiltrantes; no obstante, en algunos casos de bajo grado el pronóstico tras la cirugía ha sido bueno y no ha sido necesario tratamiento adyuvante alguno.

B I B L I O G R A F Í A a nationwide survey in Japan. J Urol. 2006;176:40-3 discussion 43.

2. Hopman AH, Moesker O, Smeets AW, Pauwels RP, Vooijs GP, Ramaekers FC. Numerical chromosome 1, 7, 9, and 11 aberrations in bladder cancer detected by in situ hybridization. Cancer Res. 1991;51:644-51.

3. Selli C, Amorosi A, Vona G, Sestini R, Travaglini F, Bartoletti R, et al. Retrospective evaluation of c-erbB-2 oncogene amplification using competitive PCR in collecting duct carcinoma of the kidney. J Urol. 1997;158:245-7.

4. Peyromaure M, Thiounn N, Scotte F, Vieillefond A, Debre B, Oudard S. Collecting duct carcinoma of the kidney: a clinicopathological study of 9 cases. J Urol. 2003;170(4 Pt 1):1138-40.

5. Motzer RJ, Bacik J, Mariani T, Russo P, Mazumdar M, Reuter V. Treatment outcome and survival associated with metastatic renal cell carcinoma of non-clear-cell histology. J Clin Oncol. 2002;20:2376-81.

6. San Miguel Fraile P, Dos Santos JE, Delgado C, Zungri Telo E, Alvarez C, Iglesias B. Carcinoma renal de los conductos colectores. Presentación de un caso y revisión de la literatura. Actas Urol Esp. 2004;28:478-83.

7. Oudard S, Banu E, Vieillefond A, Fournier L, Priou F, Medioni J, et al. Prospective multicenter phase II study of gemcitabine plus platinum salt for metastatic collecting duct carcinoma: results of a GETUG (Groupe d'Etudes des Tumeurs UroGenitales) study. J Urol. 2007;177:1698-702.

G. García-Fadrique*, M. Ramírez-Backhaus, G. Morales, J.L. Pontones y J.F. Jiménez-Cruz

Servicio de Urología, Hospital Universitario La Fe, Valencia, España

Autor para correspondencia.

Correo electrónico: gonzag1@hotmail.com (G. García-Fadrique).

\title{
Consulta diferida de un traumatismo escrotal
}

\section{Delayed scrotal trauma consultation}

\section{Sr. Director:}

El motivo de la presente es presentarle el caso de un paciente varón de 30 años aquejado de dolor testicular y teste izquierdo elevado. Relató que un mes antes sufrió un traumatismo en forma de patada en el escroto mientras jugaba con su hija de 1 año de edad. En un primer momento trató los síntomas por su cuenta, tomando Diclofenaco ${ }^{\circ}$. Unos días después observó un episodio autolimitado de hemospermia.

Debido a que el Diclofenaco ${ }^{\odot}$ era suficiente para calmar la sintomatología inicialmente, no buscó asistencia médica en un primer momento.
La exploración física revelaba un teste izquierdo ligeramente doloroso a la palpación, irregular, indurado y aumentado de tamaño respecto al teste derecho. Tenía una mínima inflamación escrotal y no había signos de hematomas.

La ecografía escrotal mostró un teste izquierdo ligeramente aumentado de tamaño con un parénquima con un patrón de ecogenicidad heterogéneo, así como la pérdida del contorno sin una clara discontinuidad de la túnica albugínea. No existía hematocele asociado. Basándose en estos hallazgos se llegó al diagnóstico de rotura testicular. El paciente optó por evitar el tratamiento quirúrgico por lo que se adoptaron medidas conservadoras.

Como alternativa a la cirugía exploradora, y dada la decisión del paciente, se realizó una RM de escroto para una 


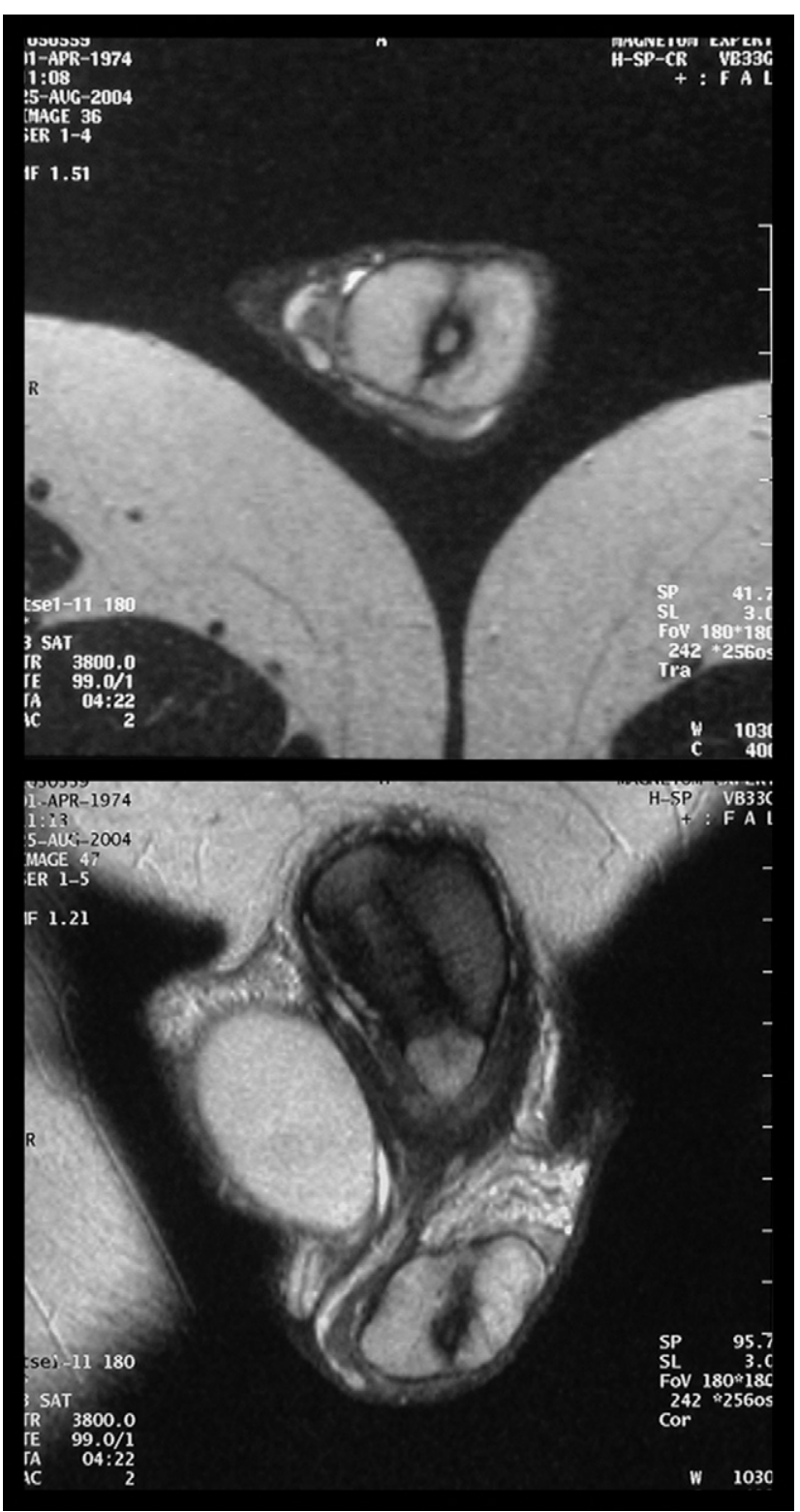

Figura 1 - Signos de hemorragia y rotura testicular apreciados en la RM.

valoración más exacta de la lesión (fig. 1). Las secuencias en T1 del testículo izquierdo mostraron un área con aumento de intensidad, secundaria a material hemorrágico. En secuencias T2, se apreciaba una señal de intensidad mixta en dicha zona, así como una marcada línea hipointensa a lo largo del parénquima testicular (fig. 1).

Se realizó un seguimiento a los 3, 6, 12 y 24 meses mediante RM. A los 24 meses se podía observar un teste izquierdo desestructurado y atrófico que refleja la evolución natural de la ruptura testicular no tratada mediante cirugía (fig. 2).

El traumatismo cerrado es la forma más frecuente de traumatismo escrotal (accidentes deportivos, accidentes de tráfico etc.). Hasta un $80 \%$ de los pacientes con traumatismo escrotal cerrado presentan lesiones testiculares o paratesticulares (contusión, hematocele, torsión testicular,

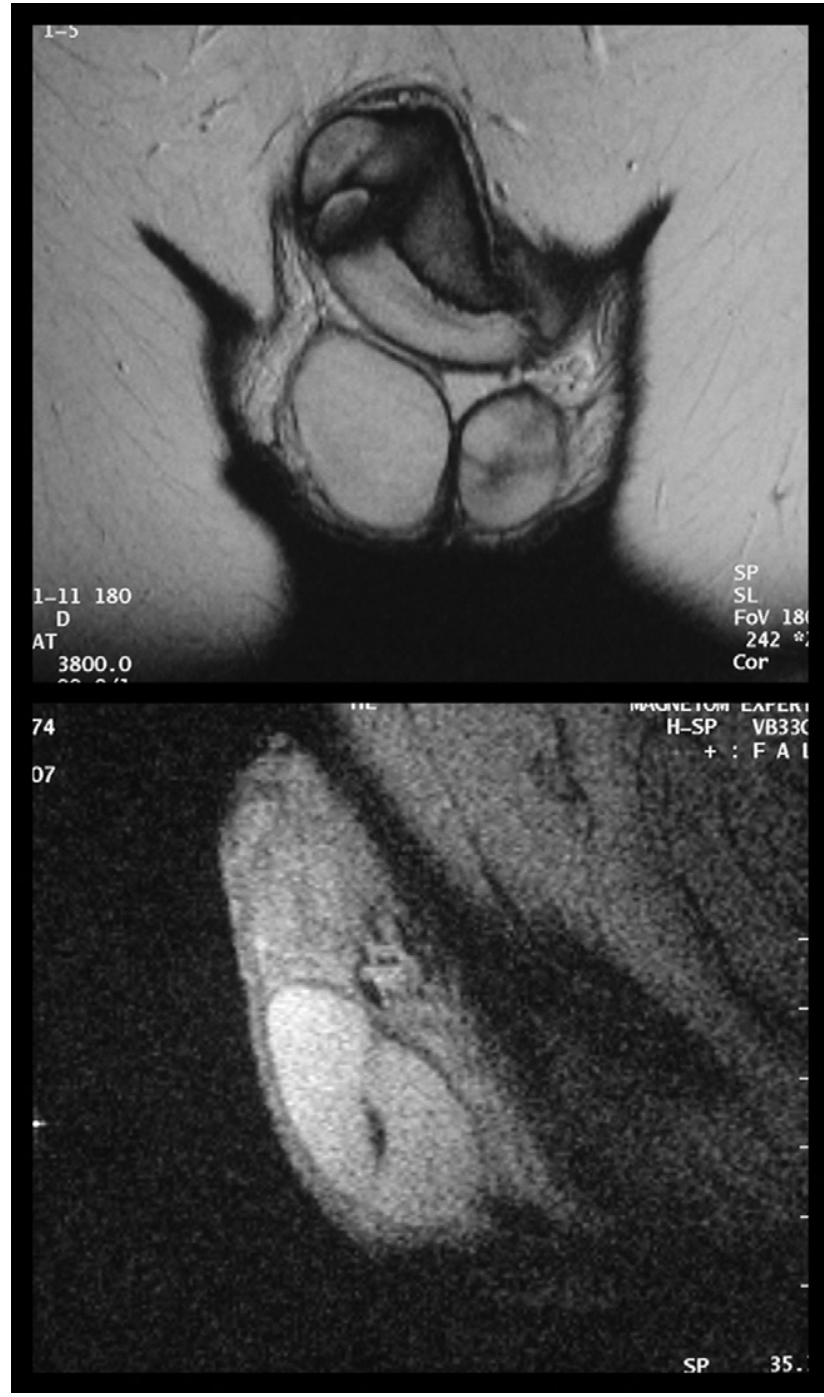

Figura 2 - Imagen de testículo atrófico, secundario a un traumatismo testicular con rotura de testículo no tratado.

hematoma testicular) y roturas testiculares en más del $40 \%$ de ellos. Hoy en día el diagnóstico se realiza mediante ecografía testicular, técnica de elección para valorar el estado de los testículos y tejidos adyacentes ${ }^{1,2}$. El rápido diagnóstico de la ruptura, basada en hallazgos ecográficos de discontinuidad de la albugínea, es crítico en estos casos ya que el tratamiento quirúrgico inmediato supone el rescate de hasta el $80-90 \%$ de los casos de los testículos lesionados. No obstante, la RM puede ser una técnica complementaria claramente indicada para aquellos casos en los que la ecografía no arroja suficiente luz al diagnóstico o los hallazgos son incompatibles con los datos clínicos. La RM aporta una imagen clara y detallada de la anatomía y ayuda a valorar la extensión de la lesión, determinado por la presencia o ausencia de hemorragia intratesticular, con valor pronóstico. Esto podría reducir el número de escrototomías exploradoras en el contexto del traumatismo testicular ${ }^{3,4}$.

La ecografía escrotal, con el hallazgo de un patrón ecográfico heterogéneo del parénquima testicular y pérdida 
del contorno de la misma, tiene una alta sensibilidad y especificidad para el diagnóstico de la rotura testicular ${ }^{4}$. El diagnóstico inmediato y la pronta reparación condicionan la viabilidad del testículo, con la preservación del parénquima testicular y su función hormonal, así como condiciona también la disminución de las complicaciones tardías, tales como el dolor crónico, la atrofia testicular y en última instancia la orquiectomía.

En ausencia de signos de severidad, el tratamiento médico con vigilancia periódica puede estar justificada. Sin embargo, ante una clínica sospechosa o hallazgos ecográficos dudosos, la mayoría de los autores recomiendan la cirugía exploradora ${ }^{5}$.

En ausencia de hematoceles, hematoma intratesticular de gran tamaño o rotura de la túnica albugínea, el tratamiento médico consistente en el reposo, la administración de fármacos antiinflamatorios y la suspensión testicular está instaurado ${ }^{6}$.

B I B L I O G R A F Í A

1. Buckley JC, McAninch JW. Diagnosis and management of testicular ruptures. Urol Clin North Am. 2006;33:111-6.
2. Andipa E, Liberopoulos K, Asvestis C. Magnetic resonance imaging and ultrasound evaluation of penile and testicular masses. World J Urol. 2004;22:382-91.

3. Pavlica P, Barozzi L. Imaging of the acute scrotum. Eur Radiol. 2001;11:220-8.

4. Deurdulian C, Mittelstaedt CA, Chong WK, Fielding JR. US of acute scrotal trauma: optimal technique,imaging findings, and management. Radiographics. 2007;27:357-69.

5. Buckley JC, McAninch JW. Use of ultrasonography for the diagnosis of testicular injuries in blunt scrotal trauma. J Urol. 2006;175:175-8.

6. Chandra RV, Dowling RJ, Ulubasoglu M, Haxhimolla H, Costello AJ. Rational approach to diagnosis and management of blunt scrotal trauma. Urology. 2007;70:230-4.

E. Tolosa Eizaguirre ${ }^{a, *}$, J.E. Robles García ${ }^{a}$, J. Lorente Pérez ${ }^{b}$ y A. Rincón Mayans ${ }^{a}$

aDepartamento de Urología, Clínica Universidad de Navarra, Pamplona, Navarra, España

bepartamento de Urología, Clínica San Miguel, Pamplona, Navarra, España

*Autor para correspondencia.

Correo electrónico: etolosaei@unav.es (E. Tolosa Eizaguirre).

\section{Hidronefrosis prenatal secundaria a válvulas ureterales}

\section{Prenatal hydronephrosis due to congenital ureteral valves}

\section{Sr. Director:}

Las válvulas ureterales representan una causa rara de obstrucción del tracto urinario superior. Desde que fueron descritas por Wolfler en 1877, muy pocos casos se han descrito en la literatura médica ${ }^{1} \mathrm{y}$, en casos aislados, han sido diagnosticadas previo a la cirugía ${ }^{2}$. En nuestro caso, la sospecha se originó antes del nacimiento, cuando las válvulas ureterales fueron consideradas durante el diagnóstico diferencial de hidronefrosis antenatal.

Presentamos el caso de un paciente de 4 meses de edad que presentó en la ecografía prenatal de control hidronefrosis severa del riñón derecho y dilatación del tercio superior del uréter. El sedimento de orina y el cultivo de orina fueron normales. El diagnóstico de hidronefrosis fue confirmado tras la realización de una ecografía 15 días después del nacimiento. La hidronefrosis fue ratificada por urografía intravenosa (fig. 1) y renograma diurético (DTPA-Tc99m/furosemida), en los cuales se observó descenso de la función y retraso en el drenaje del riñón afectado. La realización de la cistouretrografía descartó la presencia de reflujo vesicoureteral.
La pielografía anterógrada percutánea (fig. 2) confirmó y localizó de modo preciso la estenosis en el uréter proximal, sugiriendo el diagnóstico de válvula ureteral.

Ante el cuadro de hidronefrosis severa, se decidió realizar intervención quirúrgica en la que se evidenció dilatación del tercio proximal del uréter derecho, por lo que se llevó a cabo una resección de $2 \mathrm{~cm}$ de longitud del uréter, que abarcó la zona de diferencia de calibre, y anastomosis ureteroureteral término-terminal. El examen histológico del segmento ureteral resecado reveló fibras transversas de mucosa ureteral que contenían haces de musculatura lisa.

Un mes tras la cirugía, en el examen de control a través de la nefrostomía percutánea, se observó nueva reestenosis del uréter a nivel de la anastomosis ureteroureteral. Dicha reestenosis fue tratada con dilatación neumática, con resultado satisfactorio. El renograma diurético (DTPA-Tc99m/furosemida) mostró 3 años más tarde resolución completa de la hidronefrosis sin obstrucción.

La estenosis ureteral congénita y las válvulas ureterales son las principales causas de obstrucción ureteral congénita ${ }^{3}$. La embriogénesis de las válvulas ureterales se mantiene incierta, y actualmente se han sugerido tres teorías para explicar su 